\title{
Hacia un diálogo de alternativas entre la economía solidaria y la economía social: el buen vivir como horizonte descolonial
}

\author{
Towards a Dialogue of Alternatives Between Solidarity \\ Economy and Social Economy: The buen vivir Concept as \\ Decolonial Horizon
}

Agustín Ávila-Romero $\nabla^{1}$

${ }^{1}$ Universidad Federal de Goiás, Brasil (D)

\begin{abstract}
$\triangle$ agustinavila@yahoo.com
Recibido: 16 de enero del $2017 \quad$ Aprobado: 18 de julio del $2017 \quad$ Disponible en línea: 14 de enero del 2018

Cómo citar este artículo: Ávila-Romero, A. (2018). Hacia un diálogo de alternativas entre la economía solidaria y la economía social: el buen vivir como horizonte descolonial. Cooperativismo \& Desarrollo, 112(25), 78-92. doi: https://doi.org/10.16925/ co.v25i112.2033
\end{abstract}

\section{Resumen}

Propósito: este texto busca acercarse a las diferentes nociones conceptuales que giran alrededor de la economía solidaria y la economía social en diferentes espacializaciones.

Temas: en el análisis se recupera, en primer término, el concepto de economía solidaria y sus distintas implicaciones con el fin de, posteriormente, estar en capacidad de discutir los procesos descoloniales que están implícitos en las prácticas socioeconómicas de los pueblos originarios. Se anota la idea del buen vivir como una propuesta emancipadora que hace frente a los procesos de valorización del capital basados, fundamentalmente, en el despojo, la explotación y el racismo.

Desarrollo: las comunidades campesinas e indígenas de Chiapas, México, mantienen prácticas socioeconómicas y culturales con principios claros de reciprocidad y redistribución en las que, en los hechos, se dan otras formas de hacer economía y de relacionarse con la naturaleza.

Conclusiones: tanto en el norte como en el sur global se ponen en práctica procesos socioeconómicos alternativos que construyen diversos procesos, los cuales apuestan a la solidaridad económica y el buen vivir. En el caso particular de Chiapas, México, dicha dinámica se sustenta en una mirada epistémica y ontológica necesaria para observar la amplitud de experiencias sociales que se presentan.

Palabras clave: buen vivir, Chiapas, economía solidaria, prácticas socioeconómicas. 


\title{
Towards a Dialogue of Alternatives Between Solidarity Economy and Social Economy: The buen vivir Concept as Decolonial Horizon
}

\begin{abstract}
Purpose: The present work approaches the concepts that revolve around solidarity economy and social economy in different spaces.

Themes: In the first place, the concept of solidarity economy and its implications are discussed, then the decolonial processes implicit in the socioeconomic practices of indigenous peoples are considered. The notion of buen vivir (good living) is resumed as an emancipatory proposal that faces the processes of capital valorization, based mainly on dispossession, exploitation and racism.

Development: Peasant and indigenous communities of Chiapas, Mexico, maintain socioeconomic and cultural practices that demonstrate principles of reciprocity and redistribution, which confirms that there are other ways of developing economic activities and of relating to nature.

Conclusions: Both in the north and global south, alternative socioeconomic processes that are committed to economic solidarity and buen vivir (good living) are put into practice. In the case of Chiapas, Mexico, this dynamic is based on an epistemic and ontological view necessary to observe the breadth of present social experiences.
\end{abstract}

Keywords: buen vivir (good living), Chiapas, solidarity economy, socioeconomic practices.

\section{A caminho de um diálogo de alternativas entre a economia solidária e a economia social: o bem viver como horizonte descolonial}

\author{
Resumo \\ Propósito: o presente trabalho busca aproximar-se aos conceitos que giram em torno da economia \\ solidária e da economia social em diferentes espaços. \\ Temas: primeiramente, o conceito de economia solidária e as suas consequências são abordados para, \\ posteriormente, discutirmos sobre os processos descoloniais implícitos nas práticas socioeconômicas \\ dos povos originários. A noção do bem viver como proposta emancipadora que desafia os processos \\ de valorização do capital é retomada, baseados fundamentalmente na desapropriação, na exploração \\ e no racismo.
}

Desenvolvimento: as comunidades rurais e indígenas de Chiapas, no México, mantêm práticas socioeconômicas e culturais que evidenciam princípios de reciprocidade e redistribuição, o que prova que existem outras formas de fazer economia e de relacionar-se com a natureza.

Conclusões: processos socioeconômicos alternativos, que apostam na solidariedade econômica e no bem viver, são postos em prática tanto no norte quanto no sul do globo. No caso de Chiapas, a dinâmica mencionada é mantida através de uma visão epistêmica e ontológica necessária para observar a amplitude de experiências sociais presentes.

Palavras-chave: bem viver, Chiapas, economia solidária, práticas socioeconômicas. 


\section{Introducción}

Este texto pretende acercarse al estudio del impulso que realizan diversos colectivos y organizaciones en la producción de alternativas socioeconómicas que hacen frente a la actual dinámica de configuración capitalista y de funcionamiento de la mundialización.

Claro ejemplo de lo anterior son los procesos de resistencia en muchas comunidades campesinas e indígenas en las que se mantienen principios claros de reciprocidad y redistribución, y en las cuales, en los hechos, se dan otras formas de hacer economía y de relacionarse con la naturaleza.

Junto con esto, a nivel global, se observa el auge de la producción colaborativa, lo cual ocasiona hoy que muchas organizaciones, bienes y servicios como, por ejemplo, los proporcionados por el Internet- ya no respondan a los dictados de la economía capitalista y de la integración vertical y jerárquica de las empresas. Esto al punto que podemos distinguir varios procesos de economía social y solidaria caracterizados por impulsar procesos alternativos a la dinámica del capitalismo avanzado, tales como las monedas alternativas, las finanzas solidarias, las cooperativas de energías renovables, los mercados orgánicos y el comercio justo. Por otra parte, los procesos de economía social solidaria que hacen fundamento en la vida campesina e indígena y promueven la soberanía alimentaria, los derechos territoriales, culturales y ambientales, la producción orgánica, la comercialización justa y la defensa de la vida y del patrimonio biocultural y de sus sistemas de conocimientos.

En el presente análisis se recupera, en primer término, el concepto de economía solidaria y sus distintas implicaciones con el fin de, posteriormente, estar en capacidad de discutir los procesos descoloniales que están implícitos en las prácticas socioeconómicas de los pueblos originarios.

Asimismo, se señala la idea del buen vivir como una propuesta emancipadora que hace frente a los procesos de valorización del capital basados, fundamentalmente, en el despojo, la explotación y el racismo.

\section{Metodología}

A fin de llevar a cabo esta investigación, se realizó una revisión bibliográfica y hemerográfica del tema. Asimismo, se aplicaron algunas herramientas de la metodología cualitativa que permitieron llevar a cabo diferentes entrevistas semiestructuradas en el estado de Chiapas, cuyo propósito fue acercarse a la idea del buen vivir que poseen los pueblos mayas tzeltales y tojol-ab'ales. Las entrevistas se realizaron durante el mes de agosto del 2015.

\section{Fundamentos de Ecosol}

Frente a la economía capitalista, en esta fase mundializada que se caracteriza por un flujo de materiales y de energía sin precedentes para la satisfacción de bienes y servicios en escala global y en la que la superexplotación de la fuerza de trabajo y de la naturaleza son dos características fundamentales, surge desde la academia, la sociedad civil y las organizaciones otra propuesta de economía que no está basada en la búsqueda del lucro sino, sobre todo, en el beneficio colectivo. Así, la economía social y solidaria marca de manera fundamental la aspiración de las personas por tener espacios económicos centrados en las personas y no en las utilidades empresariales.

La economía social tiende a trabajar en torno a prácticas empresariales alternativas y colectivas como las que realizan las sociedades cooperativas, las asociaciones de trabajadores y las organizaciones de la sociedad civil sin fines de lucro. En cambio, la idea de economía solidaria apunta hacia un mayor cambio social y busca mudar las relaciones capitalistas mediante la lucha por la justicia, la democracia económica y la sustentabilidad ambiental.

La economía social y solidaria es así, con arreglo a sus principios, una estrategia colectiva que busca la transformación de las relaciones económicas y sociales que caracterizan el capitalismo. El gran investigador argentino José Luis Coraggio (2016, p. 15) define a la economía social solidaria como:

Un proyecto de acción colectiva (incluyendo prácticas estratégicas de transformación y cotidianas de reproducción) dirigido a contrarrestar las tendencias socialmente negativas del sistema existente, con la perspectiva - actual o potencial- de construir un sistema económico alternativo que responda al principio ético ya enunciado [la reproducción y desarrollo de la vida]. (...) La solidaridad es, sin duda, un valor moral supremo, una disposición a reconocer a los otros y velar por ellos en interés propio. 
Pero también a cooperar, a sumar recursos y responsabilidades, a proyectar colectivamente.

Frente al capitalismo salvaje actual de nuestro planeta, en el que los derechos sociales, económicos, culturales y ambientales de los ciudadanos, se subordinan a la lógica de ganancia de las empresas trasnacionales y crean graves deterioros sociales por los que se destacan la delincuencia, la emigración y la devastación ambiental, la economía solidaria propone no solo la creación de alternativas socioeconómicas basadas en la solidaridad, sino también un proyecto de superación de la crisis capitalista y la consiguiente precarización y pérdida del trabajo formal.

De esta manera:

La idea de una economía social y solidaria que supere la idea del capitalismo dominado por las trasnacionales y los monopolios y del estatismo centralizado que obedece también a grupos económicos concentradores se plantea claramente en nuestros horizontes. $Y$ es que el neoliberalismo se ha fortalecido con procesos de apertura comercial indiscriminada por parte de los países menos desarrollados, pactos internacionales y alianzas con transnacionales, que han generado una crisis en todos los sentidos, la economía decrece afectando a la mayoría de la población y las condiciones ambientales cobran día a día a las poblaciones el precio de su sobreexplotación en esta fase extractivista que solamente ha beneficiado a los grandes potentados del planeta. (Ávila, 2014, p. 53)

Por tanto, la economía solidaria impulsa la construcción de relaciones económicas alternativas en todas las esferas de la sociedad y construye procesos productivos de comercialización distinta, de finanzas solidarias y de consumo colectivo que se basan,

En el trabajo asociado, la autogestión, la propiedad colectiva de los medios de producción, la cooperación y la solidaridad. Nace de una actitud crítica frente a un modelo de desarrollo que produce riquezas generando pobreza, subordinando y explotando el trabajo y la naturaleza. Guiándose por valores no mercantiles, como la solidaridad y la democracia, la economía solidaria incorpora las dimensiones culturales, étnicas y ecológicas de la sostenibilidad del desarrollo, en el que la producción, distribución y conservación de los recursos naturales y sociales se convierten en fases en el proceso de emancipación. (Alves, 2014, p. 128)

Parte importante de los planteamientos de la economía solidaria es no solo ubicar los beneficios económicos que pueden llevar consigo los diferentes emprendimientos socioeconómicos que se ponen en marcha, sino tener claro también cómo el capitalista en esta fase de libre mercado y neoliberalismo agota profundamente los recursos naturales del planeta y ocasiona un cambio climático sin precedentes que ya empezamos a resentir en muchos países.

Dado lo anterior, investigadores como Barkin y Lemus (2011) hablan de la necesidad de unir la economía solidaria a los planteamientos de la economía ecológica, con el fin de fortalecer la perspectiva de construcción de otro tipo de economía basada en el conocimiento, según la cual la economía es un sistema abierto en el que existen flujos de materiales y de energía que deben buscar reciclarse para no exceder la capacidad de carga de la naturaleza y crear con ello los desequilibrios ambientales que generan la contaminación y los gases de efecto invernadero:

Cuando hablamos de economía solidaria estamos también hablando de economía ecológica. Estamos construyendo un proceso para fortalecer la comunidad y la sociedad, a la vez que estamos tomando en consideración los impactos de nuestras propuestas y de nuestras acciones, no sólo en cuanto a las relaciones entre los grupos sociales, sino también a los impactos que podrían tener en los ecosistemas, en el equilibrio planetario del que todos dependemos. (Barkin y Lemus, 2011, p. 3)

En ese sentido, como afirma de manera acertada el investigador de la Universidad Nacional Autónoma de México (UNAM) Víctor Manuel Toledo, la economía social y solidaria promueve además la dignificación de las personas mediante el trabajo al tener en cuenta dimensiones económicas, socioculturales, políticas y medioambientales. Sus frutos son el resultado de decisiones democráticas y participativas sobre las modalidades de producción, distribución y comercialización de los bienes y servicios producidos para la satisfacción de las necesidades colectivas e individuales (Toledo, 2016).

Resalta además que los procesos de economía solidaria tienden a fortalecerse desde una lógica territorial que es el espacio biocultural donde se 
construye la comunalidad o la socialidad de las personas. Por esto, debe impulsarse que no sean solo algunas experiencias aisladas las que se apliquen de la economía solidaria, sino como lo vemos precisamente en muchas de las comunidades indígenas de Chiapas, la economía solidaria implica integrarse en territorios, en los entramados sociales, en el diseño infraestructural y hasta en el paisaje ecológico.

Como lo afirma Corragio (2016):

Las prácticas micro-socioeconómicas de economía popular solidaria producen y reclaman una irradiación de los valores de la solidaridad y relaciones sinérgicas, más complejas que las que se propugnan al interior de cada emprendimiento o grupo de emprendimientos. Este es un primer salto cualitativo en la comprensión y las prácticas de economía solidaria, de lo micro individual a la articulación meso, del contexto inmediato dado al contexto más amplio construido. (p. 20)

En ese sentido, la economía solidaria se constituye como una propuesta transformadora y liberadora de las relaciones sociales basadas en la explotación, el lucro, la desigualdad y la distinción. Tal y como señala Moacir Gadotti (2016):

La economía solidaria no se reduce a un producto, a un objeto; se constituye en un sistema que va mucho más allá de los emprendimientos solidarios, es, sobre todo, la adopción de un concepto. La economía solidaria respeta el medio ambiente, produce sin utilizar mano de obra infantil, respeta la cultura local y lucha por la ciudadanía y la igualdad. Implica el comercio justo, la cooperación, seguridad en el trabajo, trabajo comunitario, equidad de género y consumo sustentable, producción sin sufrimiento de personas o animales.

Además de esto, en la economía solidaria el margen del "lucro" es discutido colectivamente entre el productor y el vendedor. Lo que cada uno gana es discutido colectivamente. La economía solidaria involucra a personas comprometidas con un mundo más solidario, ético y sustentable. Por eso, la economía solidaria está estrechamente ligada a la educación transformadora y a la democracia económica. (p. 75)

Así, entonces, las propuestas de economía solidaria que se ponen en marcha no se mueven en la lógica de acumulación y de lucro que buscan las empresas capitalistas, sino:

Desde su origen se definen por satisfacer las necesidades de personas, ya se trate de los trabajadores que requieren una forma de ingreso (en ocasiones con capacidades diferentes y casi siempre con problemas de inserción) o de los consumidores que requieren algún servicio y de manera preferente por ambos motivos. (Collin, 2005, p. 152)

En este sentido, es importante apuntar que regularmente las iniciativas autogestivas o formas de vida asociativas participan en reivindicaciones populares con dimensiones económicas, pero también acompañan a los campesinos que reclaman tierras, a los que no tienen vivienda, a los que piensan en otros usos del espacio urbano, a los estudiantes que reclaman mejor educación pública y, de manera muy estrecha, a los ecologistas que defienden la naturaleza, las feministas que buscan el reconocimiento de la economía del cuidado, los pueblos indígenas que defienden su territorio y sus herencias bioculturales; en general, por la emancipación de los seres humanos. Es decir, la economía solidaria acompaña con firmeza los procesos creativos de resistencia y reexistencia de los movimientos sociales contemporáneos.

De acuerdo con Gadotti (2016):

La economía solidaria constituye un fenómeno más complejo. En las últimas décadas, la economía solidaría se ha venido estructurando y constituyendo como una fuerza real y alternativa al modelo capitalista. Los términos "subterránea" e "invisible", muchas veces atribuidos a la economía popular, evidenciaban la incapacidad de los gobiernos y de la economía "oficial" de reconocer un fenómeno que no era precisamente oculto. La producción asociativa genera valores solidarios, participación, autogestión y autonomía, y la economía popular no se sustenta en los criterios de rentabilidad y de lucro del sistema capitalista. En este sentido, la economía popular tiene una perspectiva diferente al capitalismo, aunque tenga su origen en el interior de este. (p. 73)

Ahora bien, como se ha señalado en otras reflexiones (Ávila, 2011, 2012) es posible distinguir con claridad entre los procesos de economía solidaria caracterizados por impulsar procesos 
alternativos a la dinámica del capitalismo avanzado, tales como las monedas alternativas, las finanzas solidarias, las cooperativas de energías renovables, los mercados orgánicos y el comercio justo; así como distinguir, por otra parte, entre los procesos de economía solidaria que tienen fundamento en la vida campesina e indígena - y promueven la soberanía alimentaria, los derechos territoriales, culturales y ambientales, la producción orgánica, la comercialización justa y la defensa de la vida y del patrimonio biocultural-y sus sistemas de conocimiento. Esto no excluye que muchos procesos se encuentren también en las dinámicas económicas del capitalismo avanzado o en los pueblos indígenas y las comunidades campesinas.

\section{Procesos socioeconómicos en Occidente: la economía social}

Desde Occidente, lo primero que debe resaltarse es cómo, pese a ser la región del mundo en la que el capitalismo se encuentra más avanzado, existen muchas prácticas sociales y de organización social alternativas que permiten hablar de estrategias organizativas asociativas y autogestivas que abarcan diferentes sectores de la vida económica y social, y crecen de manera continua. A estos medios que permiten organizar la sociedad, Jeremy Rifkin (2014) los denomina "el procomún contemporáneo" y señala:

Estamos tan acostumbrados a creer que el Estado y el mercado capitalista son los únicos medios para organizar la sociedad que nos olvidamos de otro modelo de organización del que dependemos a diario para obtener toda una gama de bienes y servicios que no proceden del Estado ni del mercado. El procomún precede al mercado capitalista y al Estado representativo y es la forma institucionalizada más antigua de actividad autogestionada.

El procomún contemporáneo es el espacio donde miles de millones de personas participan en los aspectos más sociales de la vida. Está compuesto por literalmente millones de organizaciones autogestionadas, en su mayoría democráticas, que incluyen asociaciones benéficas, organizaciones de carácter religioso, asociaciones artísticas y culturales, fundaciones educativas, clubes deportivos no profesionales, cooperativas de productores y consumidores, cooperativas de crédito, organizaciones sanitarias, asociaciones de vecinos, grupos de apoyo y una lista interminable de instituciones formales e informales que generan el capital social de la sociedad. (Rifkin, 2014, p. 30)

Para el Consejo de la Unión Europea (2015, p. 3), el ámbito de la economía social abarca al conjunto de organizaciones basadas en la primacía de las personas sobre el capital, lo cual incluye formas organizativas tales como cooperativas, mutuales, fundaciones y asociaciones, así como nuevas formas de empresas sociales:

\begin{abstract}
Pueden ser consideradas vectores de la cohesión económica y social en Europa, ya que sirven para crear una economía social de mercado pluralista y resiliente. Actuando en el interés general, las empresas de economía social crean puestos de trabajo, aportan productos y servicios socialmente innovadores, facilitan la integración social y promueven una economía más sostenible y anclada a nivel local. Se basan en los principios de solidaridad y emancipación.
\end{abstract}

Si se analiza cómo está creciendo el sector de la economía social y solidaria en los países capitalistas más avanzados, se observa que el crecimiento es espectacular y se encuentra vinculado a sectores estratégicos de la economía, pero también a proporcionar servicios fundamentales. Rifkin (2014) señala:

Hoy, los procomunes sociales están creciendo con más rapidez que la economía de mercado en muchos países del mundo (...) la economía social es una fuerza formidable. Según un estudio realizado en 40 países por el Center for Civil Society Studies de la Universidad Johns Hopkins, los procomunes sin ánimo de lucro representan 2.2 billones de dólares... En 8 de los países estudiados -Estados Unidos, Canadá, Japón, Francia, Bélgica, Australia, República Checa y Nueva Zelanda- el sector no lucrativo representa una media del $5 \%$ del PIB, un porcentaje que en el caso de estos países supera el PIB de todos los servicios públicos; es igual al PIB del sector de la construcción y es casi igual al PIB de los bancos, las aseguradoras y los servicios financieros. (pp. 31-32)

Por su parte, Paul Mason (2016) señala:

Franjas enteras de la vida económica están empezando a moverse a un ritmo diferente en los nichos 
y huecos que deja abiertos el propio sistema de mercado. Allí han proliferado - muchos de ellos como resultado directo de la descomposición de antiguas estructuras tras la crisis de 2008- monedas paralelas, bancos de tiempo, cooperativas y espacios autogestionados; y los economistas profesionales apenas se han percatado de ello. (p. 18)

Basados en la idea fundamental de impulsar otra economía distinta a la economía capitalista convencional que genera exclusión, desempleo, desigualdad y pobreza, los impulsores de la economía social logran un crecimiento espectacular de sus iniciativas, comparadas con el desenvolvimiento de las economías capitalistas de dichos países.

Señalan que se debe:

Apostar por una nueva economía. Una economía que no mate, que sirva y no que gobierne. Que defienda el bien común y la centralidad de la persona. $\mathrm{Y}$ que se asiente sobre la capacidad que tenemos como sociedad de tejer redes y de impulsar por iniciativas comunitarias que superen el inmediatismo y el individualismo. (Caritas, 2015, p. 9)

Ana Cecilia Dinerstein (2014) destaca los extensos alcances políticos y sociales de la economía social, como "una herramienta para 'organizar la esperanza', es decir, una práctica que permite a las personas prever alternativas - prácticas futuras, relaciones y horizontes- en el presente" (p. 2; traducción propia).

No estamos hablando entonces de experimentos utópicos realizados en comunidades aisladas; el movimiento de la economía social abarca un conjunto de iniciativas que en el planeta incorpora a más de mil millones de personas según datos de la Alianza Cooperativista Internacional (ACI, 2015).

Ya hay millones de personas que traspasan aspectos de su vida económica de los mercados capitalistas al procomún colaborativo mundial. Los prosumidores no solo crean y comparten en el procomún colaborativo información, entretenimiento, energía verde, productos impresos en 3D o cursos por Internet - todo ello con un costo marginal cercano a cero-, sino que también comparten con un costo marginal muy bajo o casi nulo vehículos, viviendas, prendas de vestir y muchas cosas más mediante redes sociales, clubes de redistribución, cooperativas y sistemas de alquiler. Cada vez son más las personas que colaboran en redes de asistencia sanitaria "centradas en el paciente" para mejorar los diagnósticos y hallar nuevos tratamientos, también con un costo marginal casi nulo. $Y$ en esta nueva economía, jóvenes empresarios sociales crean empresas con "conciencia ecológica", usan el micromecenazgo para crear empresas nuevas y hasta crean monedas sociales alternativas. El resultado es que el "valor de intercambio" en el mercado está siendo reemplazado por el "valor de compartición" en el procomún colaborativo. Cuando los prosumidores comparten sus bienes y servicios en el procomún, las reglas que rigen la economía de mercado basada en el intercambio pierden importancia en la vida de la sociedad. (Rifkin, 2014, p. 34)

Entre los cambios que se ubican en el presente siglo y que están mudando la forma de funcionar del capitalismo, se tiene, por ejemplo, el acceso - si se cuenta con Internet- a diversos cursos de educación de manera virtual (muchos de ellos gratuitos pues solo se cobra el certificado), los cuales acercan a millones de personas a la posibilidad de acceder a diseños curriculares de las mejores universidades del mundo.

Una innovación importante es la utilización cada vez más creciente de la impresión en 3D. Esto posibilitará la autoproducción y la unión, sobre todo, de productores y consumidores - lo que se ha denominado "prosumidores"-, ya que la estructura horizontal que se construye en la actualidad en esta plataforma permitirá que cualquiera desde su hogar pueda imprimir la mayoría de los bienes que le son necesarios. Tal y como señala Rifkin (2014):

La democratización de la manufacturación significa que cualquier persona $-\mathrm{y}$, con el tiempo, todo el mundo- puede tener acceso a los medios de producción, y esto hará que la pregunta de quién debe poseer y controlar esos medios sea tan irrelevante como lo acabará siendo el capitalismo. (p. 122)

Los impulsos de las economías sociales y solidarias marcan la aparición fuerte de los prosumidores, así como de las monedas alternativas, con el fin de hacer frente a los desajustes e inequidades que crea el mercado capitalista, la producción asociativa de energías verdes renovables a pequeña escala, la economía colaborativa que hace posible el surgimiento de diferentes iniciativas como, por ejemplo, compartir el automóvil, la vivienda, la vestimenta, los viajes, las compras, la producción agroecológica urbana, etc.

Asimismo, Rifkin (2014) señala: 
En el procomún colaborativo, los prosumidores sustituyen a los vendedores y compradores, la libertad de compartir vence a los derechos de propiedad, el acceso cuenta más que la propiedad, las redes sustituyen a los mercados y el costo marginal de crear información, generar energía, manufacturar productos y formar a los estudiantes es casi nulo. (p. 171)

La gran disputa vendrá en torno a la privatización del eje tecnológico que permite los intercambios distintos de las economías solidarias, la discusión que gira alrededor de la neutralidad de Internet y si esta se puede romper para hacer viable que los datos de las grandes corporaciones tengan derecho de preferencia con relación a la de cualquier usuario (esta será la gran disputa en el siglo XXI). Junto con lo anterior:

La cuestión es si los prosumidores que han crecido en un entorno caracterizado por la libertad de acceso y la colaboración entre iguales hallarán un modelo de financiación que pueda optimizar el potencial que ofrece la nueva infraestructura para desarrollar una sociedad de costo marginal cercano a cero, o bien, si los intereses corporativos ligados al modelo capitalista recurrirán a la propiedad intelectual, a las políticas reguladoras y a otras leyes para controlar la infraestructura y seguir obteniendo beneficios manteniendo los precios muy por encima de un costo marginal que sería prácticamente nulo. (Rifkin, 2014, p. 175)

\section{Prácticas solidarias: una mirada desde el Sur}

En Chiapas, México, con el esfuerzo de una epistemología de la visión (Santos, 2006), es posible encontrar una infinidad de prácticas que hacen uso de los principios de la economía social y solidaria, las cuales a su vez construyen relaciones de solidaridad económica, reciprocidad y redistribución.

Por ejemplo, para los mayas tojol-ab'ales que habitan en la región fronteriza de México y Guatemala existe una cultura y una cosmovisión propia por la cual su relación con la naturaleza se realiza de otra forma, ya que para ellos todo lo que existe en el mundo tiene vida propia. Para los tojol-ab'ales abales todos formamos un conjunto de cosas dotadas de corazón, ya que el corazón es la fuente de la vida.
En las comunidades tojol-ab'ales del siglo $\mathrm{xxI}$, se evidencian prácticas de economía solidaria que perviven y hacen posible los intercambios, no importa tanto la cuestión material sino la posibilidad de intercambiar, de ofrecer reciprocidad y buscar el lajan lajan aytik ("estar parejos y estar iguales"), principio básico de la filosofía tojol-ab'al.

Entre las experiencias tojol-ab'ales de intercambio y que hacen parte de un modo particular de economía social y solidaria (Ávila, 2014, p. 65) se encuentran:

- El Koltumatel, tequio o mano vuelta. Es una actividad en la que se intercambia fuerza de trabajo y se espera que dicho acto sea devuelto por la otra persona. Cuando es época de cosecha en la tapisca de maíz la familia dueña de la parcela busca ayuda con las demás personas de la comunidad para realizar dicha actividad de trabajo; la familia antes ayudada debe devolver el trabajo prestado para la cosecha de la parcela en la otra familia. En ambos casos, al término del trabajo, se lleva a cabo un convivio con la otra familia mejor conocido como el "chich", que significa "el agradecimiento de la fuerza de trabajo prestada a través de una comida".

- El Bolmanel. Se trata de la situación en que una persona llega a intercambiar su producto por otro con una comunidad, y en la que las dos partes salen beneficiadas. El trueque aún se practica pues se puede mencionar que algunas personas de la comunidad de Rafael Ramírez, en el municipio de Las Margaritas, Chiapas, cada ocho días llegan a intercambiar los siguientes productos: café, caña, aguacate, durazno, guayaba, pepitas de calabaza, ocote y redes para cargar el pozol hacia la comunidad vecina conocida como "Saltillo", por productos como maíz, frijol, calabaza tierna y tortilla. Esta es una práctica que se daba en la época prehispánica para el intercambio comercial de productos entre distintas regiones del país.

- El trueque. Se puede manifestar de maneras distintas y es diferente al bolmanel, ya que se puede intercambiar trabajo y no solo productos. Por ejemplo, cuando una persona en una comunidad necesita ayuda representada en fuerza de trabajo (como en el caso del tequio), al término de la actividad si no se quiere pagar con fuerza de trabajo, se puede pagar con el producto sobre el cual se gastó la fuerza de trabajo; esto es un acuerdo 
tomado en el que se benefician ambas partes, en el caso de aquellas comunidades que no pagan con la moneda.

Todo este conjunto de prácticas que forman parte del patrimonio biocultural tojol-ab'al remiten a la necesidad de construir una mirada descolonizadora sobre los espacios socioterritoriales campesinos e indígenas que permita revalorizar los sistemas de conocimientos y los principios filosóficos que encontramos en las comunidades mayas del siglo xxI; en este caso, se puede hablar del buen vivir, jlekil altik en tojol-ab'al.

\section{El buen vivir como horizonte descolonial}

Plantear una ruptura con el eurocentrismo es fundamental para entender la idea del buen vivir desde un ejercicio descolonial. Para esto es necesario pensar el capitalismo como un sistema que va más allá de lo económico y en el que la explotación y el dominio político de la protesta social y la construcción hegemónica del Estado coadyuvan a la construcción de las subjetividades y de la interiorización de los sujetos sociales de las relaciones de mando y obediencia.

De acuerdo con Marañón-Pimentel (2012):

De este modo, la subjetividad, nutrida por una forma eurocéntrica de producir conocimiento, imaginario histórico y memoria histórica, naturaliza y legitima los procesos de dominación y explotación, impidiendo percibir que hay formas alternativas de conocimiento, de imaginario histórico, de memoria histórica y, por tanto de organización de la sociedad, más allá de las instituciones centrales que caracterizan la vida social en la actualidad: la familia, el trabajo asalariado, el Estado, la democracia representativa, el mercado, el patriarcalismo, el racismo, entre otras. (p. 44)

Así, entonces, tal y como han planteado Boaventura de Sousa-Santos (2006) y Gustavo Esteva (2009), la necesidad de aprender de y desde el Sur requiere de abrirse a replantear nuestras propias ideas. Es romper las nociones coloniales de la realidad y aprender de las formas de relacionarse de los pueblos indígenas y campesinos con la naturaleza, la vida, el agua y la tierra.
En este sentido, la dimensión radical de la idea del buen vivir se encuentra en el rompimiento que realiza con el pensamiento eurocentrado liberal moderno. Y esto sucede, tal como lo señala Pablo Dávalos (2008), en un momento de hegemonía capitalista en el cual solo se encuentran espacios para las disidencias, más no para las alteridades, y en el que no se permite cuestionar los supuestos civilizatorios del desarrollo.

Así, el planteamiento del buen vivir involucra la necesidad de observar las alteridades que se construyen en los espacios socioterritoriales campesinos e indígenas, fundamentalmente - aunque no de manera exclusiva-, en los que se ponen en marcha procesos de recuperación de valores, de concepción de nuevas epistemologías y filosofías de los pueblos originarios y su praxis, a través de sus herencias bioculturales, la diversidad lingüística y las prácticas comunitarias horizontales y de economía social solidaria.

Esto es relevante porque, como señala Macleod (2015, p. 104):

Este proceso se da en un contexto de globalización neoliberal y en un momento en el capitalismo de extrema depredación, de acumulación por desposesión y reprimarización de las economías latinoamericanas. No es casualidad que el concepto de sumak kawsay cobre fuerza justamente en tiempos críticos de gran destrucción ambiental, cambio climático y violencia endémica. Es un tiempo que endiosa al dinero, al consumismo desenfrenado, a los tiempos y las ganancias de corto plazo, un tiempo que fomenta el individualismo sin pensar en los demás - seres humanos y naturaleza- ni en las próximas generaciones. Es un momento de crisis, en que la hegemonía del extractivismo se impone con violencia en los territorios de los pueblos originarios, y a la vez un momento de emergencia urgente de otros paradigmas ante el carácter insostenible del modelo actual de acumulación, desigualdad y concentración de riqueza.

Así, el buen vivir es un cuestionamiento a las hegemonías políticas e intelectuales de nuestra época que construyen una idea universal basada en conceptos como desarrollo y progreso. Frente a esto, y desde la particularidad cultural y territorial del Sur global, se cuestionan las diversas formas epistémicas de construir conocimiento y las relaciones de la matriz de poder colonial basadas en 
la explotación, la construcción jerárquica de raza e inferioridad y la discriminación de género (Quijano, 2007), todo esto desde otras cosmovisiones y una ética basada, fundamentalmente, en el bien común.

Pudiésemos decir que se da como una ruptura con la mirada androcéntrica y antropocéntrica, que hemos venido cuestionando; un quiebre con la mirada dominante fundada en la separación ser humano-naturaleza, base del pensamiento del racionalismo lógico y del control del capital a través del mercado, aquella que Vandana Shiva llamó "Los monocultivos mentales". (Mejía, 2012, p. 12)

Desde la teoría de la colonialidad del poder y la noción de colonialidad del saber, no es posible visualizar los espacios construidos por los pueblos originarios como territorios neutrales, homogéneos y armónicos, sino que se visualizan como lugares en movimiento en donde el rompimiento de las concepciones coloniales visibiliza la riqueza de las prácticas culturales y de los sistemas de conocimiento de los campesinos e indígenas de Chiapas.

Desde esta perspectiva teórica recuperamos la noción de bien vivir como paradigma divergente al del desarrollo que permite pensar la vida digna desde principios distintos al consumo y la acumulación. La aproximación académica al bien vivir a la cual nos adscribimos es la que comprende el fenómeno social desde una visión histórica, que considera los aspectos económico, político y social como elementos que, entrecruzados, han constituido el actual orden social, capitalista moderno. (Olivera, 2014, p. 197)

Realizar este ejercicio descolonial del ejercicio de territorialidades con las prácticas del buen vivir permite visualizar tres grandes aportes de esta categoría:

- Otra relación no extractivista con la Naturaleza.

- Otras ontologías, epistemologías, saberes y prácticas culturales.

- Otras relaciones sociales más horizontales y democráticas.

\section{Naturaleza y buen vivir}

Dentro de la cosmovisión de los pueblos indígenas, la naturaleza no es una cosa o una mercancía, para ellos, antes que nada, la naturaleza forma parte de su vida, de sus relaciones sociales, de sus creencias y, sobre todo, de su espiritualidad. Así, la tierra antes que un valor físico o económico, es algo que merece respeto y valoración. Más cuando les dio la oportunidad de acceder a la posibilidad de tener un espacio físico para producir alimentos y buscar otros en los bosques o en las selvas, ya que la mayoría de las poblaciones indígenas pasaron por procesos de lucha social muy difíciles para acceder a la tierra (tal y como sucedió en la reforma agraria en el caso mexicano).

Para los pueblos mayas y zoques del estado de Chiapas, la naturaleza es un ser vivo; alrededor de ella construyen una religiosidad popular que tiene como base la religión católica, pero incorpora elementos de la cosmovisión maya original. Por ejemplo, se acude a pedir a los guardianes de los cerros que existan suficientes animales para proveerse de alimentos, así como presentarse en los manantiales de agua o ríos es fundamental, porque desde ahí se realizan las peticiones de lluvia que permitirán tener una buena cosecha.

Por lo tanto, los hombres y las mujeres mayas y zoques solo son un elemento más de la naturaleza, ya que señalan que dependen íntimamente de ella, lo cual significa que debe existir una buena y estrecha relación con la madre naturaleza y sus recursos; no podemos decir que el hombre domina la naturaleza, sino que el hombre es dominado por la naturaleza.

Para los zoques, el alma (el kojama) la conforman animales, plantas, minerales y fenómenos naturales; la vitalidad del hombre depende de su kojama. El individuo y su kojama están íntimamente ligados desde el nacimiento hasta la muerte. Los zoques hacen la distinción entre kojama de buena sombra, como, por ejemplo, águila, tigre, colibrí, cedro, flores, piedra, hierro y arco iris. Mientras los Mutsove o brujos tienen kojama de mala sombra, y son todos aquellos animales que poseen ponzoñas como las víboras o las avispas (Sulvarán y Ávila, 2014, p. 40 ).

Para los pueblos indígenas la matriz de todos los derechos es la tierra, en el sentido del territorio. La concepción indígena de la tierra es integral y humanista. La Tierra no es solo el suelo. La Tierra la forman los animales y las plantas, los ríos, las piedras, el aire y las aves; los seres humanos. La Tierra tiene vida. 
Es ahí cuando el buen vivir se configura desde otra concepción filosófica distinta al antropocentrismo. Roberto Diego (2013) señala lo siguiente:

Ciertamente el buen vivir viene a reconfigurar diferentes enfoques y propuestas alternativas, dándoles vitalidad en el biocentrismo que se confronta con el antropocentrismo europeo occidental, para proponer la imperiosa necesidad de entreverar lo social y la naturaleza como vía para dar un giro de 180 grados en las formas y mundos de vida de las sociedades humanas y darle un sentido distinto al devenir societal y a la vida misma en el planeta Tierra. (p. 517)

Ahora bien, esta concepción no está exenta de contradicciones, ya que, en lugares como Ecuador y Bolivia, donde a nivel de Estado se ha constituido la idea del buen vivir, sus gobiernos no han dejado de impulsar propuestas extractivistas de minerales, gas y petróleo, en detrimento de muchas poblaciones indígenas.

Lo que no queda claro en el buen vivir es cómo enfrentar sin totalitarismos al enemigo: esa otredad que se niega a renunciar a sus prebendas, de cada vez más corto plazo, dado que éste se presenta desdibujado, disperso, hasta etéreo. Así, mientras que gobiernos como los de Bolivia y Ecuador reconocen derechos a la Pachamama, al mismo tiempo refrendan concesiones para explotar recursos naturales a corporaciones trasnacionales, dejando en lo nominal esos derechos. De la misma manera, casi por inercia, continúan tratando de mejorar indicadores económicos que son piedra angular del desarrollismo, del tránsito del "subdesarrollo" al desarrollo económico, como lo es el crecimiento económico, el empleo, sin importar su tipo y qué tan digno éste sea. (Diego, 2013, p. 522)

\section{Otras ontologías y epistemologías}

Para los mayas tzeltales de Chiapas, el término Lekil kuxlejal significa "vivir bien", dentro y fuera de la familia. Lekil significa "bueno" y "bien"; kuxlejal significa "vida" o "vivir". Es la tranquilidad, la armonía, es el trabajo colectivo que une a casi todas las personas de cada comunidad, es la plenitud, todo lo bueno que pueda existir es lekil kuxlejal o "buen vivir". Si en la comunidad no hay tranquilidad, no hay acuerdos, por lo tanto, no hay lekil kuxlejal.

Se habla de lekil kuxlejal cuando todos están contentos, todos viven en paz, no hay enojos, robos, mentiras ni chismes, vivir en armonía con los animales y con la naturaleza misma. Se tiene que respetar a la naturaleza porque somos uno con ellos, lo cuidamos y ellos también nos cuidan y proporcionan alimentos para sobrevivir.

Lekil kuxlejal es estar en paz con todos, es respetar a los padres, respetar a las personas mayores y, lo más importante, es estar en paz con Dios (él nos cuida día y noche). Si hay pelea entre hermanos, vecinos y amigos, ya no sería lekil kuxlejal, pues el vivir en armonía con los hermanos permite compartir tristezas; cuando alguien fallece de la familia todos apoyan con algo sin esperar nada a cambio, la tristeza y el dolor en el corazón se comparte entre todos, eso es el lekil kuxlejal.

En lekil kuxlejal no hay competencias (tentanba' a'tel) se trabaja por igual, todos comen bien (frijol, maíz, hiervas con múltiples vitaminas y otras raíces que se dan en las milpas).

Don Gerónimo Moreno afirma:

Nosotros no nos preocupamos si comemos carne o no, ni mucho menos tener carros de lujo, ni ropas nuevas o de marcas, lo único que nos importa es vivir en armonía con todos los demás estar en paz con Dios y con la naturaleza, eso hace que vivamos muy bien y hace feliz nuestros corazones.

Paoli (2003) describe el lekil kuxlejal o el buen vivir como "la paz" o slamalil k’inal: "Para los tzeltales supone la dimensión sagrada y perfecta del silencio. Slamalil k'inal significa también 'la tranquilidad'. Hay lekil kuxlejal cuando existe slamalil k'inal" (p. 71).

El lekil kuxlejal no es una palabra con vocales y consonantes, sino que evoca algo muy grande: la vida, el estar bien con la familia, con la sociedad y la naturaleza, otra ontología en el mundo porque todo se interconecta, otras epistemologías de cómo aprehender la vida y los saberes.

El lekil kuxlejal marca esos nuevos horizontes desde los cuales las sociedades en movimiento como los pueblos indígenas de Chiapas-construyen sentidos comunitarios, lazos sociales, afectividades, defensa del territorio y perspectivas de futuro.

El lekil kuxlejal significa "solidaridad familiar”, "derecho a la educación”, "autonomía” y "libre 
toma de decisiones", "derecho al conocimiento", "valoración de los saberes tradicionales", "el derecho a la alimentación", el enlace con el ja'teletik que son los servicios comunitarios, el ch'abajel que es la reintegración comunitaria, sus propias normas de justicia (Paoli, 2003).

Como señala María Bertely (2015), en el marco de las relaciones intersocietales, el buen vivir implica conflictos, ambivalencias y dilemas: "Decidir entre todos el mejor camino para la comunidad". Esto, cuando el mal vivir supone, en sus palabras, "desarrollo e introducción de servicios públicos, carreteras y hospitales", así como "desarrollo para abatir la pobreza", con el fin de acceder a nuevos satisfactores y necesidades.

Jorge Guzmán, campesino tzeltal, resume algunas ideas fundamentales del buen vivir de la siguiente manera:

Debemos de cuidar el agua porque el agua nos da la vida; la milpa es un proceso. En pocas ocasiones, se da el buen vivir, porque a veces, al cultivar, se fumiga para que sea menos trabajo. Los apoyos del Procampo son enemigos del buen vivir. El buen vivir habla de lo bueno de la vida que viene, después de nosotros, para las personas, animales y plantas. Somos uno solo y el trabajo es un proceso, para transformar y luchar por la vida buena. Esto está presente en los consejos y, para tener una buena cosecha debes ofrecer algo en reciprocidad: "Tierra, te pido buenas plantas y te entrego esto". Por eso te aconsejan: "No lo maltrates porque esto es nuestra vida y no se consigue solo así". Ésta es la vida del territorio y hay mucho debajo del agua. (Citado por Bertely, 2015, p. 84)

Tener claras estas palabras es importante porque el proceso de expansión geográfica de capital busca destruir la buena vida de las comunidades indígenas a través del impulso de los monocultivos de grandes extensiones (como la palma africana), el desarrollo del agronegocio, la instalación de invernaderos, la minería a cielo abierto, la privatización del agua, la dependencia de los insumos agrícolas y la introducción de cultivos transgénicos.

$\mathrm{Al}$ observar los espacios de las comunidades campesinas como una disputa de territorialidades, es importante fortalecer los procesos de reafirmación cultural y apuntar de verdad a la construcción de relaciones interculturales. En ese sentido, la cultura y el territorio de los pueblos indígenas unidos a sus prácticas culturales y sus saberes son fundamentales, como lo señala Santana (2015):

La armonía con la naturaleza está amenazada. Lo más esencial de su cosmovisión está en peligro y por eso los pueblos originarios de América se propusieron «salvar al planeta y a la humanidad»; ellos piensan que sus comunidades pueden alimentar al mundo, produciendo a favor de la vida y no dependiendo de nadie, retomando sus propias tecnologías y saberes y reconstruyendo la vida del campo. (p. 184)

\section{Horizontalidad y democracia directa}

Los pueblos indígenas han sido grandes aportadores a la transformación democrática y social de México. Desde la lucha zapatista de 1994, ocuparon un lugar relevante en el propósito de finalizar la dictadura del partido de Estado (PRI) que se mantuvo durante más de 70 años.

En ese devenir, las comunidades han planteado con claridad la necesidad de que sus territorios sean autónomos dentro de la nación mexicana, a fin de estar en capacidad de defender así su cultura, la naturaleza y sus patrimonios bioculturales materiales e inmateriales.

La autonomía plantea que los pueblos indígenas decidan sobre sus territorios para regular su vida política, económica, social y cultural, así como el poder que les permita intervenir en las decisiones nacionales que los afectan (Díaz-Polanco, 2002). La autonomía implica que los pueblos indígenas tengan derechos específicos dentro del Estado nacional (Gabriel y López y Rivas, 2005).

La propuesta autonómica es el mecanismo de defensa de las prácticas de buen vivir que se presentan en las comunidades indígenas, en las que las decisiones se toman de manera colectiva en las asambleas generales de los ejidos y se busca que "quien mande, mande obedeciendo". Existe de esta manera otra forma de procesar las decisiones importantes que pasan directamente por una democracia participativa que hace posible la inclusión de todos los habitantes de una comunidad y que, poco a poco, amplían la participación de las mujeres en la vida social y política.

En ese sentido, la conformación de juntas de buen gobierno por parte del EZLN en Chiapas ha significado una serie de reconfiguraciones 
territoriales y conceptuales importantes desde una lógica descolonial.

La primera por destacar es el rompimiento de la idea colonial según la cual los indígenas requieren de agentes externos para poner en marcha sus iniciativas. Al autogobernarse de manera democrática, rotativa y horizontal, los indígenas zapatistas han demostrado que puede vivirse más allá de las limosnas gubernamentales y de forma autoorganizada.

La segunda forma - y que es clave- es el ejercicio intergeneracional que ha permitido, por un lado, el reconocimiento de los viejos como portadores de sabiduría, pero, también, de los jóvenes con sus dinámicas e iniciativas. Una nueva generación (niños y niñas en 1994) son quienes hoy dirigen sus procesos productivos, de economía solidaria, agroecología, educación y salud en un territorio geográfico similar al que ocupa el país de El Salvador.

Tercero, la interculturalidad construida desde el encuentro de los diferentes pueblos mayas y zoques de Chiapas. En cada Junta de Gobierno, no hay una sola cultura sino una diversidad de estas, en las que se hablan diferentes lenguas y se tienen diferentes costumbres. La apuesta zapatista ha sido una muestra de cómo es posible construir territorios plurales y relaciones interculturales dentro de la nación mexicana.

Sin hablar de buen vivir en el discurso, los zapatistas han mostrado al mundo su sentido práctico (que es lo más relevante). En las comunidades indígenas, se encuentra así un mosaico de prácticas sociales que permiten observar cómo se pueden construir otras relaciones sociales entre personas y con la naturaleza, así como de qué manera puede defenderse la cultura propia en contextos multiculturales y hacer frente a los procesos colonizadores y de hegemonía cultural.

Parte de ello se encuentra, también, en las luchas que se realizan en Chiapas en defensa de la madre tierra, contra la minería a cielo abierto, los monocultivos forestales y agrícolas, los transgénicos, la discriminación y el machismo. Así, se encuentra una mixtura de esfuerzos y de semillas a lo largo de Chiapas que buscan defenderse, construir y trascender la lógica capitalista actual.

En ese sentido:

Aprender a construir desde lo diverso es un reto complejo, pero nada que no se pueda lograr, por ello encontramos otras propuestas de trabajo como el lekil kuxlejal o el wach' ayon que, además de satisfacer nuestras necesidades materiales, aspiran al bienestar de nuestra sociedad y de su entorno y con esto recobrar la relación de respeto entre hombre y naturaleza. El vivir bien, más allá del esfuerzo por cumplir con determinados satisfactores, tiene una expectativa de cambio social: la perspectiva de un Estado capaz de garantizar para su población aquellas condiciones básicas de reproducción de la vida, y que tal reproducción no atente ni ponga en riesgo la generación de la biodiversidad natural (Prada, 2012). En estos procesos comunitarios, los sujetos de cambio y transformación son sus propios habitantes. En otros términos, estas prácticas comunitarias nos permiten construir un nosotros en colectivo y más amplio y diverso. (Hernández, 2016, p. 80)

Es así que el cambio social solo será posible a partir de una epistemología que valore y haga visible la pedagogía comunitaria, la cual hace viable la construcción de una ciudadanía crítica que, a su vez, recupere los valores democráticos y horizontales que se encuentran en la vida campesina y comunitaria. Todo esto, efectivamente, se da en medio de relaciones de conflicto y de poder, pero con una participación más directa de los asuntos públicos.

\section{Reflexión final}

El buen vivir como horizonte plantea el hecho de que se tiene la posibilidad de rescatar y de construir otras relaciones sociales distintas a la única modernidad posible que vende la ideología de libre mercado, la cual domina el planeta actualmente. Es urgente este planteamiento porque se vive una degradación ambiental sin precedentes que profundiza el cambio climático y los riesgos de vida de millones de personas alrededor de las zonas costeras, así como en los lugares que se verán afectados fuertemente por las sequías o el exceso de lluvias.

La buena vida como horizonte es el conjunto de iniciativas que impulsan el tejido social y la economía colaborativa, y transitan por acciones tales como: el acceso a la educación, la producción asociativa de energía verde, el libre flujo de información, la democracia económica y las monedas sociales, etc. Asimismo, ese buen vivir se encuentra expresado en la vida cotidiana de los pueblos indígenas de Chiapas donde se encuentran procesos de fomento a la agrodiversidad, la valoración del patrimonio 
biocultural y la defensa del territorio, la vida y la ecología.

Por tanto, como señala el investigador tzeltal Pedro Hernández-Luna (2016, p. 77), el principal reto al que se enfrentan las comunidades indígenas es que en un diálogo intercultural y de saberes, reconozcamos a México como una nación pluricultural y logre enfrentarse efectivamente el racismo y la discriminación:

$\mathrm{Al}$ reflexionar el caminar desde las comunidades indígenas, pensamos que los mayores obstáculos y carencias que enfrentamos obedecen a la falta de voluntad de reconocer que somos un país pluricultural. Somos muy diversos; esta diversidad no debe entenderse como obstáculo para el desarrollo, sino como una riqueza que nos permita hacer frente con diversas herramientas y estrategias a la gran crisis que estamos enfrentando. Sobre esta misma línea, encontramos expresiones múltiples que nos permiten ver otras realidades y oportunidades, trazadas desde la gente que muchas veces no han conocido la escuela pero que se ha formado desde el hacer y no en el decir. (Hernández-Luna, 2016, p. 77)

En ese camino, es fundamental romper con la colonialidad del poder, del saber y del ser. Es darse cuenta de cómo, si bien la colonialidad es constitutiva de la modernidad occidental, su lógica opresiva produce una energía de descontento, de desconfianza, de desprendimiento (Mignolo, 2016), lo que puede traducirse de manera transformadora en proyectos descoloniales que también, en última instancia, son precursores de una modernidad alternativa.

Queda entonces totalmente planteado el reto de discutir abiertamente - con aperturas epistémicas y ontológicas - las prácticas del buen vivir, a fin de llegar a un punto de discusión real sobre la diversidad cultural, tal y como afirmaba Rodolfo Stavenhagen (2012): “Tal vez ha llegado el tiempo para tomar en serio la diversidad cultural, las culturas indígenas y sus saberes y experiencias y repensar el país en función de un concepto amplio y profundo del buen vivir."

\section{Referencias}

Alves, R. M. (2014). Economía solidaria y desarrollo incluyente y sostenible. En Economía social y solidaria: hacia un desarrollo inclusivo y sostenible. Documen- to de Trabajo ort ( $4^{a}$ ed.). Campinas: Academia sobre Economía Social y Solidaria.

Ávila, A. (2011, enero-marzo). Universidades interculturales y colonialidad del saber. Revista de Educación y Desarrollo, (16), 19-26.

Ávila, A. (2012). El buen vivir: una alternativa a la crisis civilizatoria actual. En S. Sartorello, L. Ávila y A. Ávila (Coord.), El buen vivir: miradas desde adentro de Chiapas. México: Ed. Unich, Unesco, Iesalc.

Ávila, A. (2014, enero-junio). Por los caminos del mundo rural. El buen vivir tojol-ab’al de Chiapas. Revista Raizes, 34(1).

Ávila, A. (2016, julio). Contexto de la economía social turística en Chiapas, México: la Sociedad de Producción Rural de Uninajab como alternativa socioeconómica. Revista Idelcoop, (219), 45-62.

Ávila, A. y Ávila, L. (2014). Democracia económica y monedas sociales. Revista Idelcoop, (212), 50-67.

Barkin, D. y Lemus, B. (2011). La economía ecológica y solidaria: una propuesta frente a nuestra crisis. Revista Sustentabilidades, (5), 1-13.

Bertely, M. (2015, invierno). Enfoques postcoloniales y movimiento político y pedagógico intercultural en y desde Chiapas, México. Revista Relaciones, (141), $75-102$.

Caritas. (2015). Informe de economía solidaria 2015. Economías y personas. Cambiando el foco cambiamos los resultados. Madrid: Caritas.

Collin, L. (2005). Aportes para la discusión de estrategias para la creación de empleo digno y sustentable. En F. Cadena (Comp.), De la economía popular a la economía de la solidaridad (pp. 119-162). Tlaxcala: Colegio de Tlaxcala.

Coraggio, J. L. (2016). Introducción. En J. L. Coraggio (Comp.), Economía social y solidaria en movimiento. Los Polvorines: Universidad Nacional de General Sarmiento

Consejo de la Unión Europea. (2015). La promoción de la economía social como motor clave del desarrollo económico y social en Europa. Conclusiones del consejo realizado el 7 de diciembre del 2015.

Dávalos, P. (2008). Reflexiones sobre el sumak kasay el buen vivir y las teorías del desarrollo. Alainet.org. Recuperado de http://alainet.org/es/active/25617>

Díaz-Polanco, H. (2002). La izquierda hoy: desafíos y perspectivas. Memoria (México), (166), 1-11.

Diego, R. (2013). Del desarrollo al buen vivir a debate. En El retorno del desarrollo, México: UAM-X, CSH, Depto. de Producción Económica.

Dinerstein, A. C. (2014). The hidden side of social and solidarity economy-social movements and the transition of social solidarity economy into policy (Latin America). Occasional Paper 9, Potential and Limits 
of Social and Solidarity Economy. Geneva: United Nations Research Institute for Social Development.

Esteva, G. (2009). Más allá del desarrollo: la buena vida. América Latina en movimiento, (445).

Gadotti, M. (2016). Educación popular y economía solidaria. En J. L. Coraggio (Comp.), América Latina en Economía social y solidaria en movimiento (pp. 73-86). Los Polvorines: Universidad Nacional de General Sarmiento.

Hernández, P. (2016). Interculturalidad, buen vivir y derechos comunitarios en Chiapas: el ejido Jerusalén. México: Ed. UAM.

Gabriel, L. y López y Rivas, G. (2005). Autonomías indígenas en América Latina: nuevas formas de convivencia política. México: Plaza y Valdés.

Macleod, M. (2015, junio-noviembre). Buen vivir, desarrollo y depredación neoliberal en el siglo xxi. Revista Pueblos y Fronteras, 10(19), 80-108. doi: https:// doi.org/10.22201/cimsur.18704115e.2015.19.46.

Marañón-Pimentel, B. (Coord.). (2012). Solidaridad económica y potencialidades de transformación en América Latina: una perspectiva descolonial. Buenos Aires: Clacso. Disponible en http://retosalsur.org/wp-content/uploads/2013/08/Solidaridadeconomica.pdf

Mason, P. (2016). Postcapitalismo: hacia un nuevo futuro. Buenos Aires: Paidós.

Mejía, M. R. (2012, julio-diciembre). Las búsquedas del pensamiento propio desde el buen vivir y la educación popular. Urgencias de la educación latinoamericana a propósito de las relaciones entre saber y conocimiento. Revista Educación y Ciudad, (23), 9-26.

Moraes, R. y Wenderley, M. (2009). Geografía crítica la valorización del espacio. México: Ed. Ítaca.
Olivera, I. (2014). ¿Desarrollo o bien vivir? Repensando la función social de la universidad intercultural desde el cuestionamiento al efecto educativo. Revista Anthropológica, $\operatorname{XXXII(33),~179-207.~}$

Paoli, A. (2003). Educación, autonomía y lekil kuxlejal: aproximaciones sociolingüisticas a la sabiduria de los tseltales. México: Ed. UAM-Xochimilco.

Rifkin, J. (2014). La sociedad de coste marginal cero. Barcelona: Paidós.

Quijano, A. (2007). Colonialidad del poder y clasificación social. En S. Castro-Gómez y R. Grosfoguel (Eds.), El giro decolonial: reflexiones para una diversidad epistémica más allá del capitalismo global. Bogotá: Siglo del Hombre Editores.

Santana, M. E. (2015, junio-noviembre). El buen vivir, miradas desde dentro. Revista Pueblos y Fronteras, 10(19), 171-198. doi: https://doi.org/10.22201/cimsur.18704115e.2015.19.50.

Santos, B. S. (2006). Renovar la teoría crítica y reinventar la emancipación social. (Encuentros en Buenos Aires). Buenos Aires: Clacso/ubA.

Stavenhagen, R. (2012). Multiculturalismo y buen vivir. Desafíos ante la crisis actual. En Academia Mexicana de Ciencias (Coord.), Memorias de la reunión "Ciencia y Humanismo" (613-620). México: Creativa Impresores.

Sulvarán-López, J. L. y Ávila-Romero, A. (2014, enero-junio). La idea de naturaleza entre los zoques de Chiapas: Hacia la diversidad epistémica. Revista Economía y Sociedad, XVIII(30), 33-45.

Toledo, V. M. (2016). ¡Salir del capitalismo! La revolución agroecológica y la economía social y solidaria. En J. L. Coraggio (Comp.), América Latina en economía social y solidaria en movimiento (pp. 143-158). Los Polvorines: Universidad Nacional de General Sarmiento. 